MATEC Web of Conferences 13, 02022 (2014)

DOI: $10.1051 /$ matecconf/ 20141302022

(C) Owned by the authors, published by EDP Sciences, 2014

\title{
Effect of Induced Vibration on the Blood Flow Properties in a Mechanical Aortic Valve
}

\author{
Saleem Khalefa Kadhim ${ }^{1}$, a, Mohammad Shakir Nasif ${ }^{1}$, Hussain H. Al-Kayiem ${ }^{1}$, Nagarajan \\ Thirumalaiswany ${ }^{1}$ and, Rafat Al Waked ${ }^{2}$ \\ ${ }^{1}$ Mechanical Engineering Department, Universiti Teknologi PETRONAS, Ipoh - Perak, Malysia, \\ ${ }^{2}$ Mechanical Engineering, Prince Mohammad Bin Fahd University, Kingdom of Saudi Arabia.
}

\begin{abstract}
The effect of induced vibration on velocity distribution for the blood flow in the bileaflet mechanical heart valves conveying blood was investigated in this study. The bileaflet valve was simulated as an orifice. The induced vibration is due to the pulsed blood flow in the artery. Results presented in this study were performed using CFD FLUENT software. This analysis is based on the non-linear numerical solution by using a finite-element method, for the system of governing partial differential equations (continuity, momentum) of Navier - Stokes equation of blood flow through the orifice. It has been found that as the flow through the orifice increased, the vibration at the orifice inlet increased. For steady state conditions, at Reynolds number 50 the recorded frequency was $20 \mathrm{~Hz}$. When the Reynolds number increased to 100 due to the increase in the blood flow the recorded frequency increased to $30 \mathrm{~Hz}$. The increase in frequency may result in damaging the blood red cells and platelets which subsequently results in increasing the blood clogging downstream of the orifice.
\end{abstract}

\section{Introduction}

The human heart is a biological pump that moves blood throughout the human body through the circulatory system. The proper function of human heart is essential for human life. The heart is composed of four compartments (two atria and two ventricles) and these connected with two heart valves. Heart valve disease, including valvular stenosis, palaces (failure in aortic valve), may occur in the valve leading to the need for valve replacement. It has been found that $95 \%$ of patients using artificial heart valves exhibits failure in aortic valve and thus requires replacement of the coronary and aortic valves [1]. There are two types of artificial heart valves (prosthetic valve) which are mechanical prostheses, and biological valves. Mechanical prostheses valve has solid, manufactured occluders; however, the biological valve is made of tissues and has flexible occluders of animal or human origin. [2]. In this research the effects of Reynolds number and inlet velocity profile which is causes induced vibration due to blood flow circulation (Coriolis force) on the valve leaflet deflection are investigated by using computational fluid dynamics together with static structure modeling techniques. The variation of deflection that may occur at the valve leaflet due to change in blood flow is presented. This deflection may result in valve failure.

\footnotetext{
a Saleem Khalefa Kadhim: saleem.khalefa@gmail.com
}

This is an Open Access article distributed under the terms of the Creative Commons Attribution License 2.0, which permits unrestricted use, distribution, and reproduction in any medium, provided the original work is properly cited. 


\section{Mechanical heart valves}

Mechanical prostheses valve is made up from materials composition of synthetically origin such as metallic, ceramics and polymers element, whereas the biological valves might utilize synthetically materials only. It is known that biologic tissue valve is made by piggy aortic valves or fancied applying bovid pericardial tissue and hence it is appropriately treated on gluteraldehyde to conserve it and to remove antigenic proteins. Consequently, a tissue valve is rarely used in babies and young adults now. However, mechanical valves can withstand higher forces because it is made of biocompatible material which has longer life cycle and long functional capacity. Presently, mechanical valve is the preferable option for many patients with heart problems [2] and therefore, the focus of this study on the mechanical valves only. There are three types of mechanical valves and that is the Starr-Edwards caged-ball valve used in mitral valve only. The Lillehei-Kaster tilting disc valve is used to replace aortic valve but the shortcoming is that its mechanism may exhibits more deflections in the valve components resulting in damaging the valve. However, the most widely used valve is St. Jude Medical Bileaflet valve which is the main focus of this study.

\section{Modelling of the heart valve}

Using computational fluid dynamic (CFD) and fluid-structure interaction (FSI) techniques in modelling of St. Jude Medical Bileaflet valve is important; because it provides the details of the blood flow profile and subsequent vibration in the mechanical valve.

\subsection{Governance equations}

To model the mechanical valve, the blood was considered as a homogenous, and incompressible Newtonian fluid with density of $1080 \mathrm{~kg} / \mathrm{m} 3$ and a constant dynamic viscosity $\mu$ of $0.0035 \mathrm{~Pa} . \mathrm{s}$; the gravity acceleration effects were ignored. The blood flow has been considered as laminar where the Reynolds number ranged between 50 to 150 . The conservation of momentum equations that take into consideration the body and surface forces (pressure force and friction forces) which is equal to the inertia forces is represented as

$$
\left(\frac{\partial q}{\partial t}\right)+q \nabla q=-\left(\frac{1}{\rho}\right) \nabla p+\nu \nabla^{2} q
$$

Where, $\mathrm{q}$ : is a velocity vector $=\mathrm{iu}+\mathrm{jv}+\mathrm{kw}$

$\mathrm{u}, \mathrm{v}, \mathrm{w}$ : are the fluid velocity components.

$$
\nabla=\left(\frac{\partial}{\partial x}\right)+\left(\frac{\partial}{\partial y}\right)+\left(\frac{\partial}{\partial z}\right)
$$

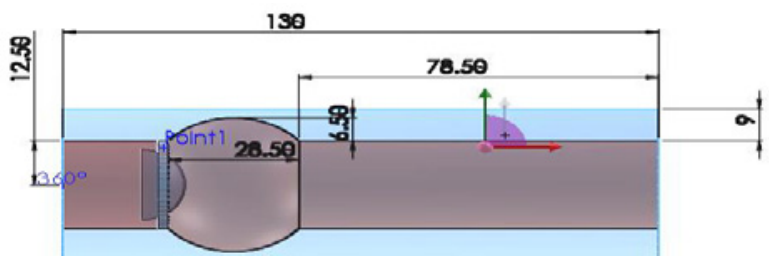

Figure 1. Sketch of the mechanical aortic valve and artery with dimensions in (mm)

The two-dimensional steady state Navier- Stokes Equations are written in Cartesian coordinates for incompressible fluids are given as:

$$
\left(\frac{\partial \rho}{\partial x}\right)=0
$$


Continuity equation:

$$
\left(\frac{\partial u}{\partial x}\right)+\left(\frac{\partial v}{\partial y}\right)=0
$$

Momentum equation in $\mathrm{x}$ - direction:

$$
\left[u\left(\frac{\partial u}{\partial x}\right)\right]+\left[v\left(\frac{\partial u}{\partial y}\right)\right]=-\left[\left(\frac{1}{\rho}\right) *\left[\left(\frac{\partial p}{\partial x}\right)\right]+v *\left[\left(\frac{\partial^{2} u}{\partial x^{2}}\right)+\left[\left(\frac{\partial^{2} u}{\partial y^{2}}\right)\right]\right]\right]
$$

Momentum equation in $\mathrm{y}$ - direction:

$$
\left[u\left(\frac{\partial v}{\partial x}\right)\right]+\left[v\left(\frac{\partial v}{\partial y}\right)\right]=-\left[\left(\frac{1}{\rho}\right) *\left[\left(\frac{\partial p}{\partial y}\right)\right]+v *\left[\left(\frac{\partial^{2} v}{\partial x^{2}}\right)+\left[\left(\frac{\partial^{2} v}{\partial y^{2}}\right)\right]\right]\right]
$$

Figs 1 and 2 show the dimensions of the aortic valve and the artery [3, and 4]. The maximum opening angle of the valve under the start conditions prior to the systole is $10^{\circ}$. However, during the diastole conditions the maximum angle of the valve is $85^{\circ}$ (Table 1). In This research, the induced vibration occurred at $75^{\circ}$ leaflet angle (full peak systole) is investigated.

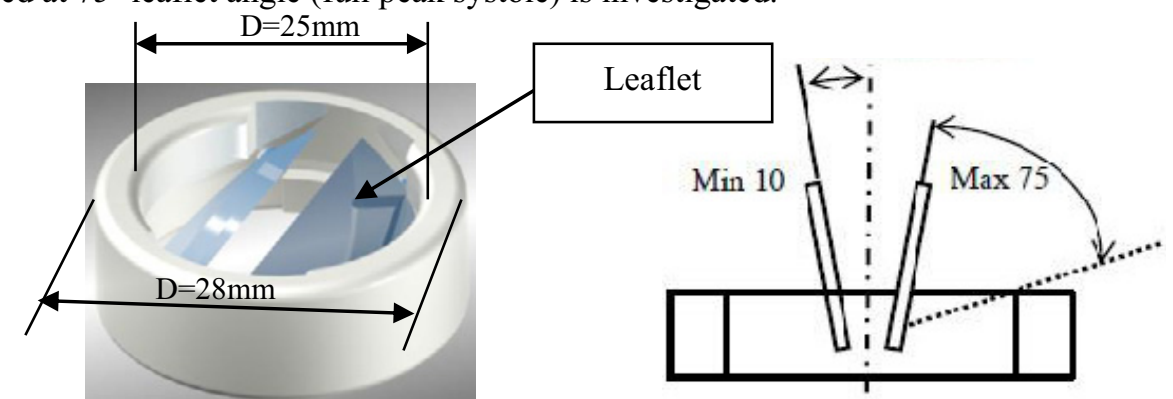

Figure 2. Model of the bileaflet aortic valve prototype

Table 1 Material property [5].

\begin{tabular}{|l|c|c|c|}
\hline \multicolumn{1}{|c|}{ Material } & Density $\left(\mathbf{K g ~ m}^{-\mathbf{3}}\right)$ & $\begin{array}{c}\text { Young's Modulus } \\
(\mathbf{M P a})\end{array}$ & $\begin{array}{c}\text { Poisson's } \\
\text { ratio }\end{array}$ \\
\hline Aortic wall & 2000 & 6 & 0.4 \\
\hline Plaque (Fibrosis) & - & 1 & 0.01 \\
\hline $\begin{array}{l}\text { Bi-leaflet valve } \\
\text { housing(Titanium) }\end{array}$ & 4500 & 20 & 0.33 \\
\hline $\begin{array}{l}\text { Bi-leaflet valve ring and } \\
\text { leaflets (pyrolytic carbon) }\end{array}$ & 1500 & 20.3 \\
\hline
\end{tabular}

For patients with artificial valve implant in their heart, the blood velocity enters the artery is $7 \mathrm{~cm} / \mathrm{s}$ [6]. Furthermore, the maximum pressure to support in the ventricle during the closing mechanical of aortic valve is $120 \mathrm{mmHg}$ [5]. Most artificial valves are made of titanium alloy (Ti 6A14V), graphite, pyrolytic carbon, and polyester. The titanium is used for the housing or outer ring, graphite coated with pyrolytic carbon is used for the bileaflet, and $100 \%$ pyrolytic carbon impregnated with tungsten is used for the inner ring [5].

\subsection{Model development and boundary conditions}

The following boundary conditions have been considered in this study

1- No slip conditions at the walls.

2- Steady state simulation

3- Fixed to support in tow end is used in the FSI model.

4- Blood temperature $37^{\circ} \mathrm{C}$. 
The number of elements used in the model is 3127602 (Fig. 3). A mesh independence study has been performed and found that increasing the number of elements beyond 3127602 will not change the results. The cells skewness was found to be 0.7 which considered acceptable.

As mentioned that fluid-structure interaction (FSI), technique is used to model the blood flow and to study the subsequent vibration generated in the aortic valve. FSI is able to model the fundamental interaction between the fluid and the valve leaflets.

\section{Results and discussion}

Fig .4 shows the velocity distribution contours; as expected for Reynolds number 50 the downstream blood velocity magnitude was less than the velocity magnitude at Reynolds number 100 . However, the highest velocity magnitude downstream of the valve is recorded at Re 150 . From the FSI model, the resultant induced vibration for the above Reynolds numbers was $20 \mathrm{~Hz}$ at Reynolds equal to 50. For Reynolds number of 150 it is found that the induced frequency has been increased to $30 \mathrm{~Hz}$.

The pressure distribution contours in the flow field (Fig. 5) show that as the Reynolds number increased from 50 to 150 , an increase in the adverse pressure of $11 \%$ is recorded at downstream of the aortic valve. From FSI results (Fig. 6) it has been found that resultant deflection due to the induced vibration at the bileaflet has increased from $0.0074 \mathrm{~mm}$ at Reynolds 50 to $0.0168 \mathrm{~mm}$ at Reynolds 150. This is attributed to the increase in the vibration (increase from $20 \mathrm{~Hz}$ at Reynolds 50 to $30 \mathrm{~Hz}$ at Reynolds 150). As shown in the figures below that the increasing of the Reynolds number for the fluid caused an increase in the vibratory amplitudes due to the increase in the blood flow velocity which resulted in increasing the amount of blood flow rotating force (Coriolis force).

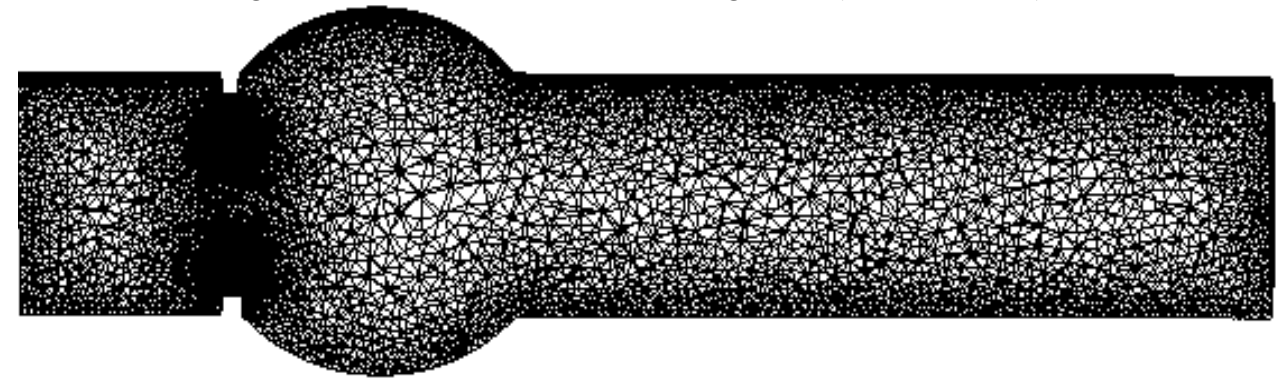

Figure 3. The meshed Geometry

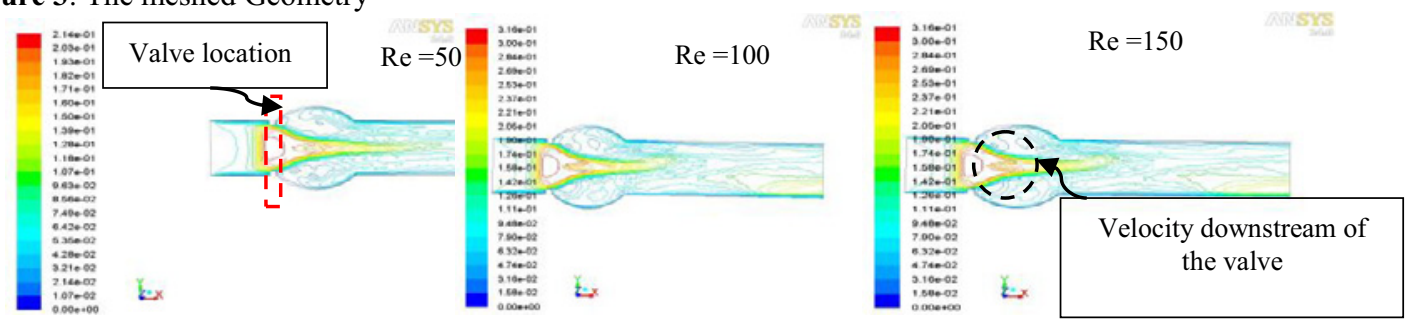

Figure 4. Velocity profile of steady state through an aortic valve in angle in peak systole at different Reynolds number.
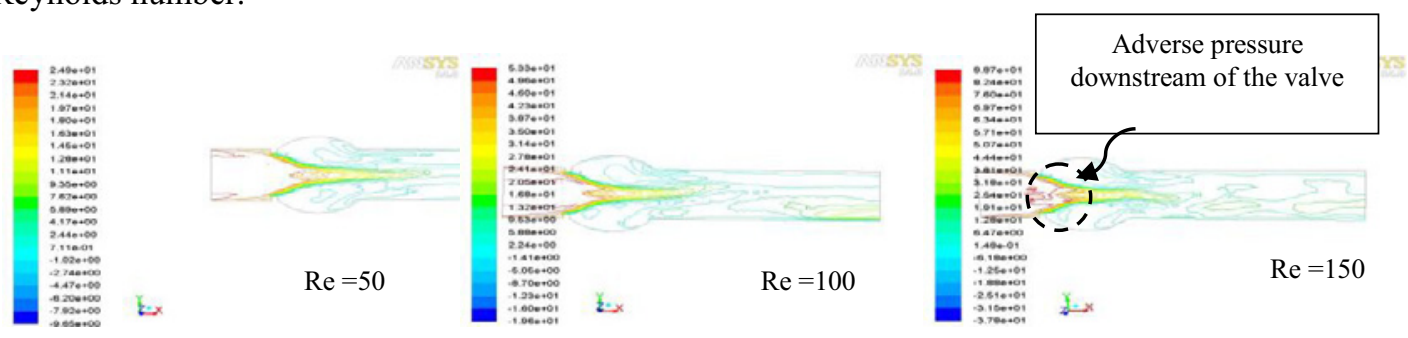
Figure 5. Total adverse pressure contours, through an aortic valve in angle in peak systole at different Reynolds number.

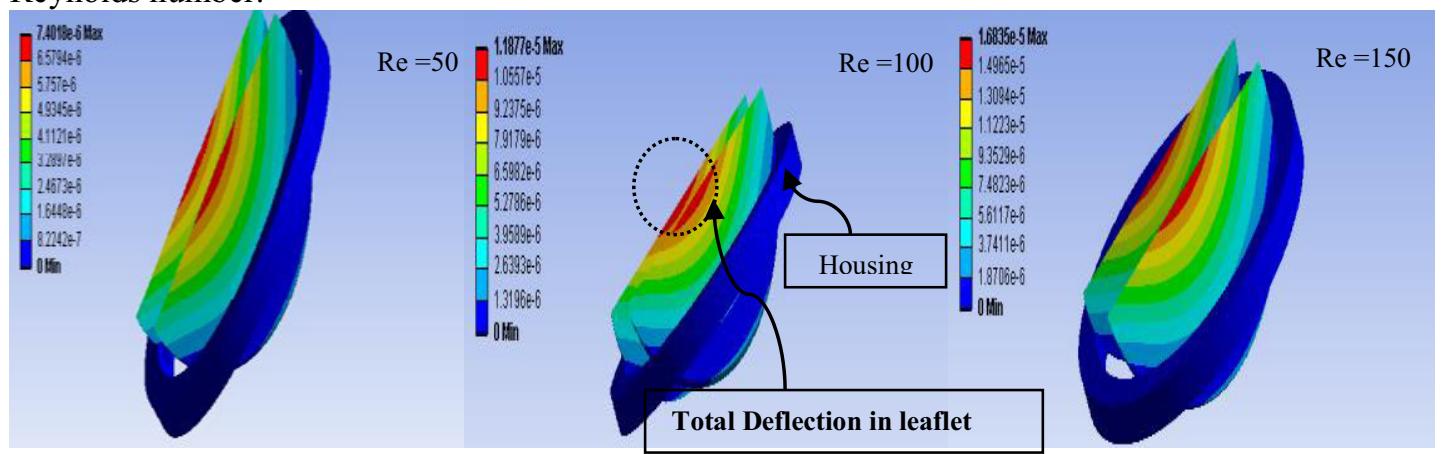

Figure 6. Total deformation contours, in aortic valve in angle in peak systole at different Reynolds number.

It can be concluded that an increase in Reynolds number from 50 to 150 resulted in $10 \%$ increase in the induced vibration frequency and $6 \%$ increase in the bileaflet valve deflection. The increase in deflection may cause bileaflet deformation and failure in the valve components (bileaflet and connecting pin). This deformation and failure will be investigated further in future studies.

\section{Conclusions}

St. Jude Medical Bileaflet artificial heart valve has been modelled and simulated using CFD and FSI techniques to model the blood flow and the resultant induced vibration. It has been found that an increase in Reynolds number from 50 to 150 resulted in 38\% increase in blood velocity and $11 \%$ increase in adverse pressure which subsequently resulted in $10 \%$ increase in the induced vibration frequency and $6 \%$ increase in the bileaflet valve deflection. The increase in deflection may cause bileaflet deformation and failure in the valve components.

\section{Acknowledgement}

The authors acknowledge Universiti Teknologi PETRONAS for sponsoring the research, and the technical assistance for the preparation and presentation of the paper.

\section{References}

1. C. Thomas, Flanagan, P. Abhay, Europ Cells and Materials, 6. 28-45, (2003).

2. N.B. Iwan, S. Dyana, Folia Medica Indonesiana, 41(2). 169-181, (2005).

3. P.N. Watton, X.Y. Luo, X. Wang, G.M. Bernacca, P. Molloy, D.J. Wheatley, J. of Biomechanics, 40. 613-626, (2007).

4. M. D. Detullio1, A. Cristallo1, E. Balaras, R. Verzicco, J. Fluid Mech. 622, 259-290, (2009).

5. C. Jamuna, M. Anburajan, International Conference Electrics Computer Technology (ICECT), 355-360, (2011).

6. E. Donohue, N. J. Quinlan, Bioengineering International Ireland Conference, 27-28, (2006). 